\title{
Overall and event-free survival are not improved by the use of myeloablative therapy following intensified chemotherapy in previously untreated patients with multiple myeloma: a prospective randomized phase 3 study
}

Christine M. Segeren, Pieter Sonneveld, Bronno van der Holt, Edo Vellenga, Alexandra J. Croockewit, Gregor E. G. Verhoef, Jan J. Cornelissen, Martijn R. Schaafsma, Marinus H. J. van Oers, Pierre W. Wijermans, Wim E. Fibbe, Shulamit Wittebol, Harry C. Schouten, Marinus van Marwijk Kooy, Douwe H. Biesma, Joke W. Baars, Rosalyn Slater, Monique M. C. Steijaert, Ivon Buijt, and Henk M. Lokhorst

We compared the efficacy of intensified chemotherapy followed by myeloablative therapy and autologous stem cell rescue with intensified chemotherapy alone in patients newly diagnosed with multiple myeloma. There were 261 eligible patients younger than 66 years with stage II/III multiple myeloma who were randomized after remission induction therapy with vincristine, adriamycin, dexamethasone (VAD) to receive intensified chemotherapy, that is, melphalan $140 \mathrm{mg} / \mathrm{m}^{2}$ administered intravenously in 2 doses of $70 \mathrm{mg} / \mathrm{m}^{2}$ (intermediate-dose melphalan [IDM]) without stem cell rescue $(n=129)$ or the same regimen followed by myeloablative therapy consisting of cyclophos- phamide, total body irradiation, and autologous stem cell reinfusion $(n=132)$. Interferon- $\alpha-2 a$ was given as maintenance. Of the eligible patients, $79 \%$ received both cycles of IDM and $79 \%$ of allocated patients actually received myeloablative treatment. The response rate (complete remission [CR] plus partial remission [PR]) was $88 \%$ in the intensified chemotherapy group versus $95 \%$ in the myeloablative treatment group. CR was significantly higher after myeloablative therapy $(13 \%$ versus $29 \% ; P=.002)$. With a median follow-up of 33 months (range, 8-65 months), the event-free survival (EFS) was not different between the treatments (median 21 months versus 22 months;
$P=.28$ ). Time to progression (TTP) was significantly longer after myeloablative treatment (25 months versus 31 months; $P=.04)$. The overall survival (OS) was not different (50 months versus 47 months; $P=.41)$. Intensified chemotherapy followed by myeloablative therapy as first-line treatment for multiple myeloma resulted in a higher $C R$ and a longer TTP when compared with intensified chemotherapy alone. However, it did not result in a better EFS and OS. (Blood. 2003;101:2144-2151)

(c) 2003 by The American Society of Hematology

\section{Introduction}

For more than 30 years administration of melphalan and prednisone has been the standard treatment for multiple myeloma (MM), resulting in a median overall survival of 30 months to 36 months. ${ }^{1-4}$ From 1983, high-dose melphalan (HDM; $140 \mathrm{mg} / \mathrm{m}^{2}$ ) was used to overcome resistance to conventional doses of alkylating agents. ${ }^{5,6}$ Since then, high-dose therapy supported by stem cell rescue has been explored in phase 1 and phase 2 studies of MM. ${ }^{7-18}$ So far, only one randomized study demonstrated that standard chemotherapy followed by myeloablative treatment improved survival, as compared with chemotherapy alone. ${ }^{19}$ This study has been criticized because a relatively poor response in the conventionally treated patients was observed. ${ }^{20}$ Based on these results, several randomized studies have addressed the issue of intensive therapy versus standard treatment. ${ }^{21-23}$

In November 1995 the Dutch-Belgian Hemato-Oncology Cooperative Study Group (HOVON) started a prospective multicenter phase 3 trial to study the efficacy of myeloablative therapy with stem cell rescue added to intensified chemotherapy compared with intensified chemotherapy alone. The study was closed April 1, 2000. We now report the results of the first analysis of this study.

\section{Patients, materials, and methods}

\section{Criteria for enrollment}

Patients up to 65 years of age with previously untreated MM and stage II or III A/B disease according to the Salmon and Durie criteria were eligible for the study. ${ }^{24}$ Criteria for exclusion were World Health Organization (WHO) performance status 4; severe cardiac, pulmonary, neurologic, or metabolic disease; inadequate liver function (ie, bilirubin level $\geq 2.5$ times the upper limit of normal value); prior malignant disease except nonmelanoma skin tumors or stage 0 cervical carcinoma; and prior extensive radiotherapy involving the myelum, which could preclude total body irradiation. At registration, WHO performance up to 4 was allowed because an improvement of disease-related morbidity could be expected after remission induction. Hemodialysis or treatment for hypercalcemia with pamidronate was instituted when needed. All patients had given written informed
From the Erasmus Medical Center Rotterdam (Erasmus MC) and University Medical Center Utrecht (UMCU) for the Dutch-Belgian Hemato-Oncology Cooperative Study Group (HOVON), The Netherlands.

Submitted March 20, 2002; accepted September 5, 2002. Prepublished online as Blood First Edition Paper, November 27, 2002; DOI 10.1182/blood-2002-030889

Supported by the National Health Council of The Netherlands.
Reprints: Christine M. Segeren, Leiden University Medical Center, Department of Clinical Oncology, K1-P, PO Box 9600, 2300 RC Leiden, The Netherlands; e-mail: c.m.segeren@lumc.nl.

The publication costs of this article were defrayed in part by page charge payment. Therefore, and solely to indicate this fact, this article is hereby marked "advertisement" in accordance with 18 U.S.C. section 1734

(C) 2003 by The American Society of Hematology 
consent before inclusion. The study was performed according to the Helsinki agreement.

\section{Study protocol and remission induction treatment}

The treatment protocol is outlined in Figure 1. Patients were treated with 3 to 4 cycles of vincristine, adriamycin, dexamethasone (VAD) for remission induction. The VAD regimen consisted of daily doses of $0.4 \mathrm{mg}$ vincristine and $9 \mathrm{mg} / \mathrm{m}^{2}$ doxorubicin administered by rapid intravenous infusion for 4 consecutive days as described previously. ${ }^{25}$ Dexamethasone $(40 \mathrm{mg}$ ) was given orally on days 1 to 4 on even cycles and on days 1 to 4,9 to 12 , and 17 to 20 on odd cycles of VAD. The treatment cycles were repeated at 4-week intervals. Antibacterial and antifungal prophylaxis was given according to local guidelines. All patients received continuous bisphosphonates according to local protocols.

\section{Randomization}

After induction treatment with VAD, patients were randomly assigned to one of the 2 treatment groups irrespective of their responses to VAD. Randomization was stratified by center. Exclusion criteria for randomization were WHO performance status 3 or 4, severe cardiac disease (WHO grade $\geq 3$ ), inadequate liver function, or persistent serum creatinin of more than or equal to $177 \mu \mathrm{M}$. Patients younger than 56 years with a human leukocyte antigen (HLA)-identical sibling were candidates for allogeneic stem cell transplantation (allo-SCT), in which case they were not eligible for randomization.

\section{Peripheral stem cell harvest}

At 4 to 6 weeks after the last cycle of VAD, peripheral blood stem cells were collected after cyclophosphamide (4 $\mathrm{g} / \mathrm{m}^{2}$ intravenously, day 1) and granulocyte colony-stimulating factor (G-CSF; Amgen, Thousand Oaks, CA; $300 \mu \mathrm{g} / \mathrm{d}$ subcutaneously for patients under $75 \mathrm{~kg}$, otherwise $480 \mu \mathrm{g} / \mathrm{d}$ ) starting at day 5 until the last day of leukapheresis. Peripheral blood stem cell collection was started as soon as the white blood cell (WBC) count reached $1.0 \times 10^{9} / \mathrm{L}$ and more than or equal to $1 \% \mathrm{CD} 34^{+}$cells were present in the peripheral blood. A minimum of $5 \times 10^{6} \mathrm{CD} 34^{+}$cells $/ \mathrm{kg}$ and/or $10 \times 10^{4}$ granulocyte-macrophage colony-forming units (CFU$\mathrm{GM}) / \mathrm{kg}$ were required in order to proceed to myeloablative treatment. Bone marrow harvesting was performed if stem cell collection failed and at least $2 \times 10^{8} / \mathrm{kg}$ nucleated bone marrow cells were harvested.

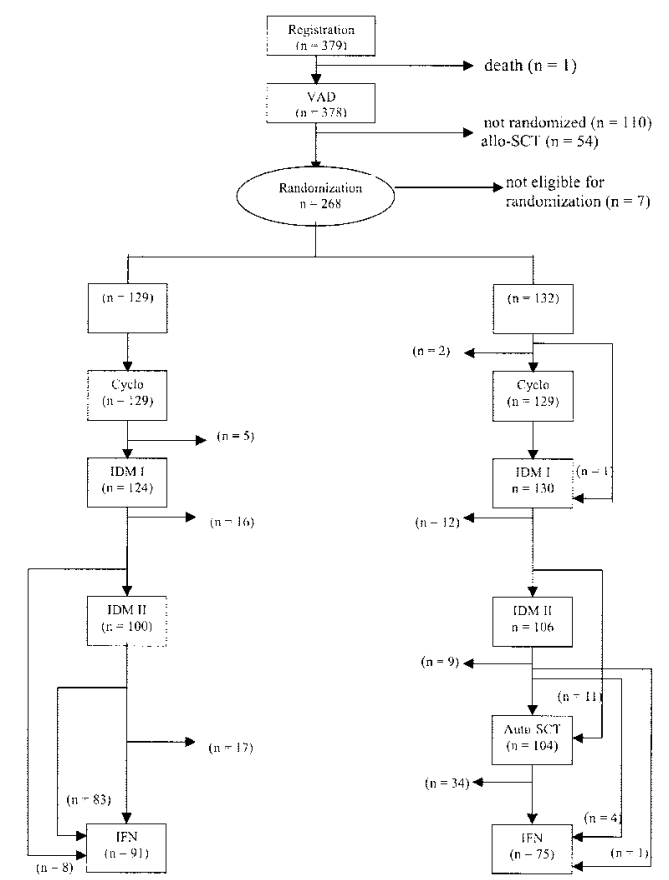

Figure 1. Outline of the study and completion of allocated treatment. Cyclo indicates cyclophosphamide.

\section{Intensification with melphalan}

Melphalan $\left(140 \mathrm{mg} / \mathrm{m}^{2}\right)$ was administered intravenously, divided in 2 cycles of $70 \mathrm{mg} / \mathrm{m}^{2}$ (intermediate-dose melphalan [IDM]) without stem cell rescue. IDM was given in the outpatient clinic as a slow bolus injection with hyperhydration and forced diuresis as described previously. ${ }^{26}$ An antibacterial and antifungal prophylaxis was given according to local guidelines. Prophylactic G-CSF was started on day +4 after melphalan at a daily dose of $300 \mu \mathrm{g}$ to $480 \mu \mathrm{g}$ subcutaneously and continued until the neutrophil count had recovered to more than or equal to $1.0 \times 10^{9} / \mathrm{L}$. Prophylactic platelet transfusions were given once the platelet count dropped to levels less than or equal to $10 \times 10^{9} / \mathrm{L}$. A second cycle of IDM with G-CSF was administered maximally 8 weeks after the first IDM except when aplasia persisted (neutrophils $\leq 0.5 \times 10^{9} / \mathrm{L}$ at day 30 and/or platelets $\leq 50 \times$ $10^{9} / \mathrm{L}$ at day 42 ). If hematopoietic recovery had not occurred at 8 weeks after IDM I or IDM II, autologous stem cell rescue with $2.5 \times 10^{6} / \mathrm{kg}$ $\mathrm{CD} 34^{+}$cells was allowed.

\section{Myeloablative treatment and autologous peripheral blood stem cell reinfusion}

Patients who were randomized for myeloablative treatment proceeded to this regimen if at least a partial remission had been achieved and an adequate stem cell graft was available. Exclusion criteria were WHO performance status $\geq 3$, severe organ dysfunction, or serum creatinine, bilirubin, and transaminases of more than or equal to 2.5 times the upper limit of normal values. The myeloablative regimen consisted of $60 \mathrm{mg} / \mathrm{kg}$ cyclophosphamide given twice on 2 consecutive days followed by total body irradiation with lung shielding ( $9 \mathrm{~Gy}$; lung dose, $8 \mathrm{~Gy}$ ). Fractionated body irradiation of $2 \times 5$ Gy or $2 \times 6$ Gy was allowed.

\section{Interferon- $\alpha-2 a$ maintenance}

Treatment with interferon- $\alpha-2 \mathrm{a}$ (IFN; $3 \times 10^{6} \mathrm{U}$ thrice weekly) was started 60 to 90 days after the second cycle of IDM or 60 to 90 days after transplantation and was continued until relapse or progression in those patients who had reached at least a partial remission and a WHO performance status of 0 to 2 in the absence of severe organ dysfunction with a platelet count more than $50 \times 10^{9} / \mathrm{L}$ and a neutrophil count more than $1.0 \times 10^{9} / \mathrm{L}$.

\section{Evaluation of response}

Partial response (PR) was defined as a $50 \%$ or more reduction of monoclonal immunoglobulins (M-protein) in serum and/or urine or more than $50 \%$ reduction of bone marrow infiltration in nonsecretory myeloma. Complete response (CR) was defined as no M-protein measurable in serum and/or 10 times concentrated urine by immunofixation analysis and less than $5 \%$ plasma cells which had to be polyclonal by immunofluorescence staining. Relapse from CR was defined as recurrence of monoclonal plasma cells in the bone marrow or recurrence of M-protein in serum and/or urine measured by immunofixation. Progression from PR was defined as a doubling of M-protein on 2 consecutive measurements or any increase of M-protein in the presence of clinical evidence of disease progression.

\section{Cytogenetic studies}

Bone marrow samples were cultured in RPMI with $6 \%$ to $10 \%$ serum and in Iscoves medium containing interleukin 4 and/or interleukin 6 and harvested after 24 and 96 hours according to standard cytogenetic techniques. The metaphase preparations were stained for RFA-, QFQ-, or GTG-banding and karyotypes were described according to the international nomenclature. ${ }^{27}$ Where possible, a minimum of 20 cells was analyzed. The presence of a clonal abnormality was defined as 2 metaphases with the same additional chromosome or the same structural abnormality or as 3 metaphases missing the same chromosome. When only one abnormal metaphase was found, the clonality of the abnormalities observed had to be confirmed with fluorescence in situ hybridization (FISH). Cases with a normal karyotype where less than 20 cells were analyzed were considered failures. 


\section{Quality of life study}

Quality of life was assessed using the European Organization for Research and Treatment of Cancer Quality of Life Questionnaire C30 (EORTC QLQ-C30) questionnaire. ${ }^{28}$ This questionnaire includes a global health and quality of life scale, 5 functioning scales (physical, role, cognitive, emotional, and social), 3 symptom scales (fatigue, nausea, and vomiting), and a number of single items. Questionnaires were presented to patients prior to start of treatment, at evaluation of each treatment phase, and every 3 months thereafter for 2 years. Quality of life measurements were stopped at time of relapse or progression.

\section{Statistical analysis}

All patients who fulfilled the eligibility criteria after VAD were randomized between the 2 treatment groups. This study was designed to reveal a $15 \%$ increase in 2-year-long event-free survival (EFS) from randomization from $40 \%$ to $55 \%$ in the myeloablative group. With a 2 -sided significance level $\alpha=0.05$ and a power $1-\beta=0.80,170$ patients were required in each treatment group and 178 events had to be observed. ${ }^{29}$ It was assumed that $90 \%$ of the patients should be randomized. Therefore, the intention was to enter 400 patients in 4 years time. Ultimately, 453 patients were registered, 12 of whom were not eligible. There were 311 patients (71\%) randomized, 8 of whom were not eligible for randomization. In order to have complete data of the patients in this analysis, the analysis was restricted to eligible patients who were registered before August 1, 1999. Thus, 261 patients were included: 129 in the intensified chemotherapy group and 132 in the myeloablative treatment group. The present analysis was performed in November 2001. The number of events for event-free survival in the groups was 179: 94 in the intensified chemotherapy group and 85 in the myeloablative therapy group.

Patient characteristics between the 2 treatment arms were compared using the Pearson chi-squared test or the Fisher exact test, whichever was appropriate, in case of discrete variables, or the Wilcoxon rank-sum test in case of continuous variables. End points in the study included response rate, event-free survival, time to progression (TTP), and overall survival (OS) from randomization. EFS was determined from the date of randomization until no response after IDM, progression/relapse after previous response, or death without progression, whichever came first. Patients who still had no response after IDM were considered failures at one day after randomization. TTP was calculated from the date of randomization until progression/ relapse or death due to MM. Patients without progression who died from other causes were censored at date of death. OS was measured from date of randomization until death. Patients still alive at the date of last contact were censored. EFS, TTP, and OS were estimated by the Kaplan-Meier method, and Kaplan-Meier curves were generated to illustrate differences between the 2 treatment arms and compared using the log-rank test. The analysis was by intention-to-treat and the patients who were eligible for randomization were analyzed according to the treatment arm to which they were assigned.

The quality of life analysis and the cost analysis were performed by applying the Mann-Whitney $U$ test.

The variables at diagnosis that were included in the analysis of prognostic factors are shown in Table 1. Univariate survival analysis was performed with Cox regression to determine differences in survival between subgroups. The variables that appeared significant in the univariate analysis were also included in a backward selection multivariate Cox regression. The multivariate Cox regression started with all significant variables, and the variable with the largest $P$ value was removed, until all remaining variables had a $P$ value of less than .05 . All reported $P$ values are 2 -sided and a significance level $\alpha=0.05$ was used.

\section{Results}

\section{Patient characteristics}

From November 1995 until April 2000, 453 patients from 46 centers were registered. There were 12 patients who were found not eligible because of double registration $(n=2)$, prior treatment with

\begin{tabular}{|c|c|c|c|}
\hline Characteristics & $\begin{array}{l}\text { All registered } \\
\text { patients, } \\
n=379\end{array}$ & $\begin{array}{c}\text { Intensified } \\
\text { chemotherapy, } \\
n=129\end{array}$ & $\begin{array}{c}\text { Myeloablative } \\
\text { therapy, } \\
n=132\end{array}$ \\
\hline Age in years, median (range) & $55(31-65)$ & $55(38-65)$ & $56(32-65)$ \\
\hline Male/female & $235 / 144$ & $74 / 55$ & $81 / 51$ \\
\hline \multicolumn{4}{|l|}{ WHO performance } \\
\hline $0-1$ & 297 & 108 & 107 \\
\hline $2-3$ & 78 & 19 & 25 \\
\hline Not done & 4 & 2 & 0 \\
\hline \multicolumn{4}{|l|}{ Stage (Salmon and Durie) } \\
\hline IIA & 75 & 32 & 27 \\
\hline IIB & 5 & 0 & 2 \\
\hline IIIA & 259 & 89 & 93 \\
\hline IIIB & 40 & 8 & 10 \\
\hline \multicolumn{4}{|l|}{ Monoclonal protein } \\
\hline $\lg A$ & 98 & 40 & 34 \\
\hline $\lg G$ & 215 & 70 & 78 \\
\hline $\lg D$ & 9 & 3 & 3 \\
\hline LcD & 42 & 11 & 11 \\
\hline Nonsecreting myeloma & 15 & 5 & 6 \\
\hline \multicolumn{4}{|l|}{ Hemoglobin level less than or } \\
\hline equal to $6.21 \mathrm{mM}$ & 136 & 49 & 39 \\
\hline \multicolumn{4}{|l|}{ Serum calcium greater than } \\
\hline $2.65 \mathrm{mM}$ & 45 & 8 & 12 \\
\hline Serum LDH greater than ULN & 55 & 23 & 14 \\
\hline \multicolumn{4}{|l|}{ Serum $\beta_{2}$-microglobulin } \\
\hline $0-3$ & 155 & 55 & 62 \\
\hline Greater than $3 \mathrm{mg} / \mathrm{L}$ & 170 & 49 & 60 \\
\hline Not done & 54 & 25 & 10 \\
\hline \multicolumn{4}{|l|}{ Bone marrow plasma cells } \\
\hline Less than or equal to $50 \%$ & 221 & 75 & 79 \\
\hline Greater than $50 \%$ & 125 & 38 & 45 \\
\hline Not done & 33 & 16 & 8 \\
\hline \multicolumn{4}{|l|}{ Number of skeletal lesions } \\
\hline 0 & 75 & 31 & 24 \\
\hline $1-2$ & 59 & 18 & 23 \\
\hline At least 3 & 243 & 80 & 85 \\
\hline Not done & 2 & 0 & 0 \\
\hline
\end{tabular}

chlorambucil $(\mathrm{n}=1)$, stage I disease or monoclonal gammopathy of undetermined significance (MGUS; $n=3$ ), primary amyloidosis $(n=3)$, prior chemotherapy for lung carcinoma $(n=1)$, extensive radiotherapy precluding total body irradiation $(n=1)$, or poor pulmonary function $(\mathrm{n}=1)$.

In February 2001 a first analysis of this trial had to be performed per the regulations of the Dutch National Health Council. In order to have complete data of the patients in that analysis (all patients should be in follow-up or still be treated with IFN maintenance), it was decided to restrict the analysis to the 379 eligible patients registered before August 1, 1999. In November 2001, the results of these patients were updated and are presented here.

Progression from prior diagnosed plasma cell disorders occurred in $8 \%$ of the 379 patients: 13 patients from MGUS, 12 from plasmacytoma, 4 from stage I disease, and 2 from smoldering myeloma. There were 268 patients who proceeded to randomization. There were 7 patients who were unjustly randomized (ie, 4 patients had persistent renal failure and in 3 patients allo-SCT was planned). Thus, 261 patients were eligible for randomization. Of these, 129 were randomized to intensified chemotherapy alone and 132 were randomized to myeloablative treatment added to intensified chemotherapy. There were 111 patients who were not randomized. There were 54 patients who had an HLA-identical sibling and proceeded to allo-SCT and 16 patients who died before or during VAD. Other reasons for not being randomized were persistent renal 
Table 2. Partial or complete remission reached on protocol

\begin{tabular}{lcc}
\hline & $\begin{array}{c}\text { Intensified chemotherapy, } \\
\mathrm{n}=129, \%\end{array}$ & $\begin{array}{c}\text { Myeloablative therapy, } \\
\mathrm{n}=132, \%\end{array}$ \\
\hline VAD & 71 & 69 \\
IDM I & 82 & 85 \\
IDM II & 88 & 91 \\
PBSCT & NA & 95 \\
IFN- $\alpha-2 a$ & 88 & 95
\end{tabular}

NA indicates not applicable.

failure $(n=6)$, no response to treatment or progressive disease $(n=12)$, excessive toxicity or poor performance status $(n=13)$, refusal $(n=7)$, or other $(n=3)$. Patient characteristics at time of diagnosis are shown in Table 1.

\section{Completion of allocated treatment}

In 258 of 261 randomized patients, cyclophosphamide and G-CSF were administered. In 10 patients no leukapheresis was performed due to insufficient stem cell mobilization $(n=5)$, toxicity $(n=3)$, early death $(n=1)$, or refusal $(n=1)$. Peripheral blood stem cells were collected in 248 patients and bone marrow was harvested in 2 patients. The median number of $\mathrm{CD}^{+} 4^{+}$cells harvested was $9.9 \times 10^{6} / \mathrm{kg}$ (range, $0.3 \times 10^{6} / \mathrm{kg}-76.7 \times 10^{6} / \mathrm{kg}$ ). In 244 patients an adequate graft for autografting was obtained. In 17 patients no sufficient graft was obtained. Consequently, these patients did not proceed to myeloablative therapy.

Of 261 randomized patients, 254 received the first cycle of IDM, that is, 124 patients (96\%) in the intensified chemotherapy group and 130 patients $(98 \%)$ in the myeloablative therapy group. There were 7 patients who did not receive melphalan because of progressive or resistant disease $(n=2)$, excessive toxicity $(n=3)$, or refusal $(n=2)$. Of 261 randomized patients, 206 patients $(79 \%)$ actually received $140 \mathrm{mg} / \mathrm{m}^{2}$ melphalan divided in 2 cycles, equally divided over the 2 groups. There were 48 patients who received only one cycle of IDM because of no response or progressive disease $(n=10)$, excessive toxicity or poor performance status $(n=27)$, or other reasons $(n=11)$. There were 11 patients who proceeded to myeloablative treatment after only one cycle of IDM. These patients did not receive the second cycle because of incomplete hematologic recovery. However, these patients proceeded to myeloablative therapy because a sufficient stem cell graft was available. There were 104 randomized patients (79\%) who proceeded to myeloablative treatment with stem cell rescue, 11 patients after 1 cycle of IDM and 93 patients after 2 cycles of IDM.

There were 5 patients who did not achieve a CR or PR, but only stable disease at retrospective treatment evaluation, who proceeded to myeloablative therapy.

In 13 patients, myeloablative therapy with stem cell rescue was not performed because of no response or progressive disease $(n=3)$, excessive toxicity or poor performance status $(n=5)$, absence of a graft $(n=3)$, or other $(n=2)$. IFN was started in 91

Table 3. Complete remission on protocol

\begin{tabular}{lccc}
\hline & $\begin{array}{c}\text { Intensified } \\
\text { chemotherapy } \\
\text { alone, } \mathrm{n}=129, \%\end{array}$ & $\begin{array}{c}\text { Myeloablative } \\
\text { therapy, } \\
\mathrm{n}=132, \%\end{array}$ & $P$ \\
\hline VAD & 1 & 5 & $\mathrm{NS}$ \\
IDM I & 6 & 8 & $\mathrm{NS}$ \\
IDM II & 10 & 17 & .12 \\
PBSCT & - & 27 & $\mathrm{NS}$ \\
IFN- $\alpha-2 \mathrm{a}$ & 13 & 29 & .002 \\
\hline
\end{tabular}

NS indicates not significant; - , not applicable.

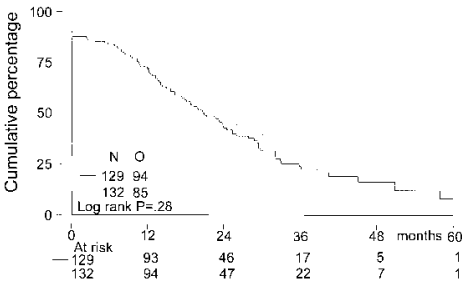

Figure 2. Kaplan-Meier curves of event-free survival. The solid line indicates after intensified chemotherapy; dotted line, after myeloablative therapy with autologous stem cell rescue; $\mathrm{O}$, observed events.

patients $(71 \%)$ in the intensified chemotherapy group as compared with 75 patients $(57 \%)$ in the myeloablative therapy group. Substantially fewer patients proceeded to IFN after myeloablative therapy primarily due to thrombocytopenia or poor performance. The median duration of IFN treatment was 8 months: 12 months in the intensified chemotherapy group and 7 months in the myeloablative therapy group $(P=.11$; hazard ratio $1.3,95 \%$ confidence interval $[\mathrm{CI}]=0.9-1.9)$. Reasons for stopping IFN were toxicity ( $\mathrm{n}=72 ; 29$ in the intensified chemotherapy group and 43 in the myeloablative therapy group), relapse or progression $(n=54 ; 39$ in the intensified chemotherapy group and 15 in the myeloablative therapy group), refusal $(n=3)$, or other $(n=3)$. The completion of allocated treatment is shown in Figure 1.

\section{Response}

The overall response rate (PR and CR) of all 379 registered patients on VAD was $63 \%$ (CR 2\%). There were 12 patients who died before response evaluation (3\%), 30\% of patients had no response, $2 \%$ had progressive disease, and in $2 \%$ of patients the response was unknown.

The overall response rate after VAD in the 261 randomized patients was $70 \%$ (CR 3\%), which increased to $90 \%$ after 2 cycles of IDM. A partial response after transplantation was achieved in 5 patients who were not in PR or CR before myeloablative treatment with stem cell rescue. Of 261 randomized patients, 239 eventually achieved a PR or CR. In patients randomized to intensified chemotherapy the response rate was $88 \%$ and in patients randomized to myeloablative therapy following intensified chemotherapy the response rate was $95 \%$. The cumulative response rate after each treatment phase is presented in Table 2.

After 2 cycles of IDM, $10 \%$ of patients in the intensified chemotherapy group had achieved a CR as compared with $17 \%$ in the myeloablative therapy group $(P=.12)$. The overall $\mathrm{CR}$ rate on protocol was $13 \%$ in the intensified chemotherapy group and $29 \%$ in the myeloablative therapy group $(P=.002$, Table 3$)$.

\section{Event-free survival, time to progression, and overall survival}

The median follow-up for all patients was 27 months. The median follow-up from randomization of the 156 patients still alive was 33 months (range, 8-65 months). There was no significant difference

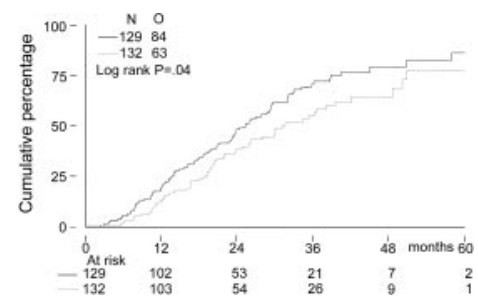

Figure 3. Kaplan-Meier curves of time to progression. The solid line indicates after intensified chemotherapy; dotted line, after myeloablative therapy with autologous stem cell rescue; and $\mathrm{O}$, observed events. 


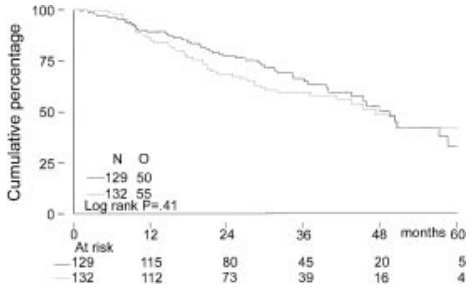

Figure 4. Kaplan-Meier curves of overall survival. The solid line indicates afte intensified chemotherapy; dotted line, after myeloablative therapy with autologous stem cell rescue; and $\mathrm{O}$, observed events.

in EFS from randomization between the 2 treatment groups. The median EFS was 21 months in the intensified chemotherapy group versus 22 months in the myeloablative therapy group $(P=.28$; hazard ratio $=0.85,95 \% \mathrm{CI}=0.63-1.14$, Figure 2$)$. The TTP was longer in patients with myeloablative therapy ( 25 months versus 31 months; $P=.04$; hazard ratio $=0.70,95 \% \mathrm{CI}=0.5-0.98$, Figure $3)$. The median OS from randomization was 50 months in the intensified chemotherapy group versus 47 months in the myeloablative therapy group $(P=.41$; hazard ratio $=1.17,95 \% \mathrm{CI}=0.80$ 1.72, Figure 4). Overall survival from $\mathrm{CR}$ was not different between the 2 treatment groups for patients who achieved a CR. TTP and OS were also calculated for randomized patients who were actually eligible for further treatment after evaluation of the last IDM (91 patients in the intensified chemotherapy group and 106 patients in the myeloablative therapy group). Median TTP from evaluation after IDM was 22 months in the intensified chemotherapy group and 27 months in the myeloablative therapy group $(P=.02$; hazard ratio $=0.64,95 \% \mathrm{CI}=0.44-0.94)$. The median OS from date of evaluation of the last IDM was not significantly different between the 2 treatment groups (45 months versus 46 months, $P=.11$; hazard ratio $=1.48,95 \%$ $\mathrm{CI}=0.92-2.36$ ).

\section{Prognostic factors}

Univariate Cox regression showed that stage III disease, hemoglobin level less than or equal to $6.21 \mathrm{mM}, \beta_{2}$-microglobulin more than $3 \mathrm{mg} / \mathrm{L}$ after VAD, elevated lactate dehydrogenase (LDH), plasma cell labeling index more than $1 \%$ (all $P<.01$ ), $\beta_{2^{-}}$ microglobulin more than $3 \mathrm{mg} / \mathrm{L}$ at diagnosis, and skeletal lesions $(P<.05)$ were associated with shorter EFS. Treatment arm was not of prognostic relevance. In the multivariate analysis only a hemoglobin level less than or equal to $6.21 \mathrm{mM}$ and elevated LDH remained statistically significant $(P<.001$, Table 4$)$.

It appeared that the prognostic factors for EFS were also predictive for TTP, in the univariate as well as in the multivariate analysis. This is not completely unexpected, as almost all patients achieved at least a PR before transplantation or the start of IFN (Table 5). In addition, elevated calcium levels and randomization to intensified chemotherapy were adverse prognostic factors for TTP in the univariate analysis.

Univariate Cox regression showed that stage B disease, a hemoglobin level less than or equal to $6.21 \mathrm{mM}, \beta_{2}$-microglobulin more than $3 \mathrm{mg} / \mathrm{L}$ at diagnosis, elevated $\mathrm{LDH}$, multiple skeletal lesions, $\beta_{2}$-microglobulin more than $3 \mathrm{mg} / \mathrm{L}$ after VAD (all $P<.01$ ), older age, and stage III disease (both $P<.05$ ) predicted for inferior OS from randomization. Hemoglobin level less than or equal to $6.21 \mathrm{mM}$, elevated LDH (both $P<0.01$ ), skeletal lesions, stage $B$ disease, and $\beta_{2}$-microglobulin more than $3 \mathrm{mg} / \mathrm{L}$ at diagnosis $(P<.05)$ remained statistically significant in the multivariate analysis for OS (Table 6).

\section{Cytogenetic studies}

Cytogenetic analysis was performed in 120 of 379 registered patients in designated centers. In 98 patients cytogenetic studies were successful. Chromosomal abnormalities were detected in 44 of 98 patients (45\%), of whom 22 showed hyperdiploidy (50\%), 9 showed hypodiploidy (20\%), 6 were pseudodiploid (14\%), and 7 were not classifiable $(16 \%)$.

In $21(48 \%)$ of 44 patients chromosome 1p/q abnormalities were found. Monosomy 13 or deletions of $13 q$ were present in 19 patients. There was a strong association between chromosome $1 \mathrm{p} / \mathrm{q}$ abnormalities and those of chromosome $13(P=.01)$; 14 patients had both abnormalities. In the multivariate analysis of this group of patients only chromosome $1 \mathrm{p} / \mathrm{q}$ abnormalities predicted for inferior EFS $(P=.009)$, TTP $(P<.001)$, and OS $(P=.003)$.

\section{Toxicity and causes of death}

Common Toxicity Criteria (CTC) grades 3 and 4 were observed in $9 \%$ of patients during the first cycle of IDM and in 5\% during the second cycle of IDM. Mucositis, nausea, vomiting, and hemorrhage were the most frequent side effects. The frequency of WHO grade 3 or 4 infections was $13 \%$ during both the first and the second cycle of IDM. Myeloablative treatment was associated with $45 \%$ grade 3 or 4 toxicity. Infection grade 3 or 4 was observed in $44 \%$ of the patients. The toxicity data of IDM and myeloablative therapy are shown in Table 7 and Table 8.

Treatment related mortality (TRM) was $0.8 \%$ after the first cycle and $0.5 \%$ after the second cycle of IDM. TRM within 3 months after myeloablative therapy was $3.9 \%$.

In the intensified treatment group, 50 patients have died; 34 from relapse or progression, 3 from other malignancies, 5 from infections, 1 from interstitial pneumonia, 3 from hemorrhage, and 4 from other reasons. In the myeloablative therapy group, 55 patients have died; 33 from relapse or progression, 4 from interstitial pneumonia, 9 from infections, 3 from respiratory insufficiency, 1 from hemorrhage, and 5 from other reasons.

Table 4. Univariate and multivariate Cox regression analysis of risk factors for event-free survival

\begin{tabular}{|c|c|c|c|c|c|c|}
\hline \multirow[b]{2}{*}{ Risk factor } & \multicolumn{2}{|c|}{ Univariate analysis } & \multirow[b]{2}{*}{$P$} & \multicolumn{2}{|c|}{ Multivariate analysis } & \multirow[b]{2}{*}{$P$} \\
\hline & $\mathrm{HR}$ & $95 \% \mathrm{Cl}$ & & $\mathrm{HR}$ & $95 \% \mathrm{Cl}$ & \\
\hline Stage III disease & 1.6 & $1.1-2.4$ & .009 & - & - & NS \\
\hline $\mathrm{Hb}$ level less than or equal to $6.21 \mathrm{mM}$ & 1.7 & $1.2-2.3$ & $<.001$ & 1.9 & 1.3-2.6 & .001 \\
\hline$\beta_{2}$-microglobulin greater than $3 \mathrm{mg} / \mathrm{L}$ & 1.4 & $1.0-2.0$ & .03 & - & - & NS \\
\hline LDH greater than ULN & 2.2 & $1.5-3.3$ & $<.001$ & 2.5 & $1.6-3.8$ & $<.001$ \\
\hline Plasma cells LI greater than $1 \%$ & 2.6 & $1.3-5.2$ & .005 & - & - & $\mathrm{NI}$ \\
\hline$\beta_{2}$-microglobulin greater than $3 \mathrm{mg} / \mathrm{L}$ after VAD & 2.0 & $1.3-3.1$ & $<.001$ & - & - & $\mathrm{NI}$ \\
\hline Skeletal lesions ( 0 vs $1-2$ vs $\geq 3$ ) & 1.2 & $1.0-1.5$ & .03 & - & - & NS \\
\hline Myeloablative treatment & 0.9 & $0.6-1.1$ & .28 & - & - & $\mathrm{NI}$ \\
\hline
\end{tabular}

HR indicates hazard ratio; - , not applicable; NS, not significant; $\mathrm{Hb}$, hemoglobin; $\mathrm{NI}$, not included in multivariate analysis. 
Table 5. Univariate and multivariate Cox regression analysis of risk factors for time to progression

\begin{tabular}{|c|c|c|c|c|c|c|}
\hline \multirow[b]{2}{*}{ Risk factor } & \multicolumn{2}{|c|}{ Univariate analysis } & \multirow[b]{2}{*}{$P$} & \multicolumn{2}{|c|}{ Multivariate analysis } & \multirow[b]{2}{*}{$P$} \\
\hline & $\mathrm{HR}$ & $95 \% \mathrm{Cl}$ & & $\mathrm{HR}$ & $95 \% \mathrm{Cl}$ & \\
\hline Stage III disease & 1.9 & $1.2-2.8$ & .004 & - & - & NS \\
\hline $\mathrm{Hb}$ level less than or equal to $6.21 \mathrm{mM}$ & 1.9 & $1.4-2.7$ & $<.001$ & 2.0 & $1.4-3.0$ & $<.001$ \\
\hline Calcium greater than $2.65 \mathrm{mM}$ & 1.7 & $1.1-2.6$ & .02 & - & - & NS \\
\hline$\beta_{2}$-microglobulin greater than $3 \mathrm{mg} / \mathrm{L}$ & 1.6 & $1.1-2.3$ & .02 & - & - & NS \\
\hline LDH greater than ULN & 2.1 & 1.3-3.2 & .002 & 2.2 & 1.3-3.5 & .002 \\
\hline Plasma cells LI greater than $1 \%$ & 2.7 & 1.3-5.6 & .008 & - & - & $\mathrm{NI}$ \\
\hline$\beta_{2}$-microglobulin greater than $3 \mathrm{mg} / \mathrm{L}$ after VAD & 1.9 & $1.2-3.1$ & .006 & - & - & $\mathrm{NI}$ \\
\hline Skeletal lesions ( 0 vs $1-2$ vs 3 or more) & 1.3 & $1.0-1.6$ & .03 & - & - & NS \\
\hline Response on VAD & 0.9 & $0.6-1.3$ & .48 & - & - & $\mathrm{NI}$ \\
\hline Myeloablative treatment & 0.7 & $0.5-1.0$ & .04 & - & - & NS \\
\hline
\end{tabular}

HR indicates hazard ratio; - , not applicable; NS, not significant; $\mathrm{Hb}$, hemoglobin; NI, not included in multivariate analysis.

\section{Hematologic recovery}

After the first cycle of IDM, WBC count reached more than or equal to $1.0 \times 10^{9} / \mathrm{L}$ after a median of 20 days (range, $0-61$ days) and platelets more than or equal to $20 \times 10^{9} / \mathrm{L}$ after a median of 22 days (range, 0-61 days). After the second cycle of IDM, WBC recovery was identical. Platelet recovery however was slower: a median of 27 days (range, 0-126 days). Autologous stem cell reinfusion after myeloablative treatment resulted in rapid hematopoietic recovery: WBC count reached more than or equal to $1.0 \times 10^{9} / \mathrm{L}$ after a median of 13 days (range, 0-48 days) and platelets reached more than or equal to $20 \times 10^{9} / \mathrm{L}$ after a median of 11 days (range, 0-145 days). Stem cell rescue was given in 8 patients after the first cycle of IDM (7 patients in the intensified chemotherapy group) and in 8 patients after the second cycle of IDM ( 7 patients in the intensified chemotherapy group) because of persistent bone marrow aplasia. In the myeloablative therapy group only the patients who needed stem cell rescue after the second cycle of IDM proceeded to myeloablative therapy.

\section{Quality of life assessment}

Quality of life was assessed at 3,6,9, and 12 months during the first year of follow-up. During this period functioning was worse in many domains and symptoms were more persistent after myeloablative therapy, with the following relevant differences remaining statistically significant even at 12 months: overall quality of life $(P<.05)$, role functioning $(P<.05)$, and social functioning $(P<.001)$. Patients had more financial problems after myeloablative treatment $(P<.05)$. More patients in the myeloablative therapy group had complaints of pain $(P<.05)$, loss of appetite $(P<.05)$, and fatigue $(P<.001)$ when compared with the intensified chemotherapy alone.

\section{Discussion}

The observation that the achievement of a complete remission increases the probability of prolonged EFS and OS in MM has prompted several groups to explore dose-escalation regimens including double transplantation. . $1-23,30,31^{-}$

This randomized study was designed to evaluate whether patients who are treated with high-dose chemotherapy benefit from additional myeloablative treatment. Intensified chemotherapy was administered as 2 separate cycles of $70 \mathrm{mg} / \mathrm{m}^{2}$ melphalan given intravenously (intermediate-dose melphalan [IDM]). Myeloablative treatment following intensive chemotherapy resulted in a higher CR rate and a longer TTP. EFS and OS however were not improved after a median follow-up of 33 months from randomization.

The largest experience with repeated myeloablative treatments has been achieved at the University of Arkansas in the Total Therapy Program. ${ }^{30,31}$ It was observed that the response may increase from $65 \%$ after induction to $75 \%$ after the first and $83 \%$ after the second myeloablative treatment including $41 \%$ complete responses. ${ }^{31}$ In a comparative analysis with case-matched registered controls receiving conventional chemotherapy, double transplantation was superior with regard to response rate $(86 \%$ versus $52 \%, P=.0001$ ), median EFS (49 months versus 22 months, $P=.0001)$, and OS (62 months versus 48 months, $P=.0130$ ). However, the value of repeated intensive therapy still needs prospective evaluation. In 1994, a randomized study was initiated in France to compare the efficacy of single transplantation with double transplantation. After a median follow-up of 4 years EFS and OS were comparable (median 24 and 48 months in the single and 30 and 54 months in the double transplantation group). ${ }^{21}$ Remarkably, only patients with good prognostic profile, that is, a

Table 6. Univariate and multivariate Cox regression analysis of risk factors for overall survival

\begin{tabular}{|c|c|c|c|c|c|c|}
\hline \multirow[b]{2}{*}{ Risk factor } & \multicolumn{2}{|c|}{ Univariate analysis } & \multirow[b]{2}{*}{$P$} & \multicolumn{2}{|c|}{ Multivariate analysis } & \multirow[b]{2}{*}{$P$} \\
\hline & $\mathrm{HR}$ & $95 \% \mathrm{Cl}$ & & $\mathrm{HR}$ & $95 \% \mathrm{Cl}$ & \\
\hline Age, continuous & 1.03 & $1.0-1.07$ & .03 & - & - & NS \\
\hline Stage III disease & 1.9 & $1.1-3.2$ & .01 & - & - & NS \\
\hline Stage B disease & 2.6 & $1.5-4.7$ & .001 & 2.2 & $1.0-4.8$ & .04 \\
\hline $\mathrm{Hb}$ level less than or equal to $6.21 \mathrm{mM}$ & 1.8 & $1.2-2.7$ & .004 & 2.0 & $1.3-3.2$ & .003 \\
\hline$\beta_{2}$-microglobulin greater than $3 \mathrm{mg} / \mathrm{L}$ & 2.3 & $1.5-3.5$ & $<.001$ & 1.6 & $1.0-2.6$ & .04 \\
\hline LDH greater than ULN & 2.4 & $1.5-3.9$ & $<.001$ & 2.1 & $1.2-3.5$ & .007 \\
\hline$\beta_{2}$-microglobulin greater than $3 \mathrm{mg} / \mathrm{L}$ after VAD & 3.2 & $1.9-5.3$ & $<.001$ & - & - & $\mathrm{NI}$ \\
\hline Skeletal lesions ( 0 vs $1-2$ vs $\geq 3$ ) & 1.4 & $1.1-1.9$ & .006 & 1.4 & $0.1-1.9$ & .03 \\
\hline Myeloablative treatment & 1.2 & $0.8-1.7$ & .41 & - & - & $\mathrm{NI}$ \\
\hline
\end{tabular}

HR indicates hazard ratio; - , not applicable; NS, not significant; $\mathrm{Hb}$, hemoglobin; NI, not included in multivariate analysis. 
$\beta_{2}$-microglobulin less than $3 \mathrm{mg} / \mathrm{L}$, had a significantly better OS after double transplantation. ${ }^{32}$ The first interim analysis of the Italian 1996 clinical trial in which single and double intensive therapies were compared in 178 patients did not show a significant difference in $\mathrm{CR}$ or OS between both groups after a median follow-up of 30 months. ${ }^{22}$ Preliminary results from the French group "Myélome Autogreffe" also did not show a significant benefit of double intensive therapy over single intensive therapy. ${ }^{23}$

An important issue of this study is the lack of any survival benefit from myeloablative therapy over intensive chemotherapy alone. Other high-dose therapy studies have shown a longer overall survival with myeloablative therapy only. ${ }^{11,17,19,21,30}$ Apparently in the present study the better CR rate and longer TTP of the combined treatment do not translate into a better survival. This suggests that the extra number of CRs induced by the second treatment are generally of limited duration. A potential explanation is the high proportion of high-risk patients in this study, which is reflected by $77 \%$ of patients with stage III disease and a high percentage of patients with $\beta_{2}$-microglobulin more than $3 \mathrm{mg} / \mathrm{L}$. Other studies have shown that remissions obtained in poor-risk patients are generally of short duration and ultimately result in relapse. Second, cyclophosphamide and total body irradiation as a myeloablative regimen in our study may have an antimyeloma effect that is inferior to high-dose melphalan which is used in most protocols today. Such a restricted antimyeloma effect may also contribute to the fact that clinical CRs in this group do not persist. Recently, 2 studies have shown that total body irradiation plus melphalan used as myeloablative treatment does not lead to improved survival over melphalan therapy alone. ${ }^{33,34}$ The use of a non-total body irradiation conditioning regimen has also been related with prolonged progression-free survival (PFS) and OS by the European BMT registry. ${ }^{35}$ The combined data of the present study and the recently published French study suggest that total body irradiation and cyclophosphamide should no longer be used as a myeloablative regimen in MM. The use of total body irradiation in our study may also have contributed to the reduced quality of life after myeloablative treatment when compared with intensified chemotherapy alone and the fact that a higher number of patients had to stop IFN due to excessive toxicity.

Recently, a number of studies have shown that chromosome 13 deletions associated with high $\beta_{2}$-microglobulin are strong adverse prognostic factors for EFS and OS after conventional and highdose therapy including tandem transplantation..$^{31,36-38}$ In most of

Table 7. Nonhematologic toxicity CTC 2-4 grade after intermediate-dose melphalan (IDM) cycles I and II (\%) and myeloablative treatment

\begin{tabular}{lccc}
\hline & \multicolumn{2}{c}{ Treatment period } & \\
\cline { 2 - 4 } & $\begin{array}{c}\text { IDM cycle 1, } \\
\mathrm{n}=254\end{array}$ & $\begin{array}{c}\text { IDM cycle 2, } \\
\mathrm{n}=206\end{array}$ & $\begin{array}{c}\text { Myeloablative } \\
\text { therapy, } \mathrm{n}=104\end{array}$ \\
\hline Liver & 2 & 1 & 13 \\
Mucositis & 9 & 6 & 45 \\
Nausea & 11 & 11 & 22 \\
Vomiting & 7 & 8 & 18 \\
Diarrhea & 4 & 3 & 20 \\
Renal & 2 & 1 & 3 \\
Fever & 4 & 3 & 18 \\
Allergy & 2 & 2 & 3 \\
Cutaneous & 6 & 3 & 12 \\
Cardiac & 2 & 1 & 6 \\
Neurologic & 2 & 2 & 5 \\
Other & 11 & 11 & 34 \\
Maximum CTC 2 & 28 & 26 & 31 \\
Maximum CTC 3 & 7 & 4 & 28 \\
Maximum CTC 4 & 2 & 1 & 17 \\
\hline
\end{tabular}

Table 8. Infections WHO grade 2-4 after intermediate-dose melphalan (IDM) cycles I and II (\%) and myeloablative treatment

\begin{tabular}{lccc}
\hline & \multicolumn{2}{c}{ Treatment period } & \\
\cline { 2 - 3 } & $\begin{array}{l}\text { IDM cycle 1, } \\
\mathrm{n}=254\end{array}$ & $\begin{array}{c}\text { IDM cycle 2, } \\
\mathrm{n}=206\end{array}$ & $\begin{array}{c}\text { Myeloablative } \\
\text { therapy, } \mathrm{n}=104\end{array}$ \\
\hline Septicemia & 9 & 8 & 41 \\
Lung & 6 & 4 & 15 \\
Ear/nose/throat & 7 & 5 & 10 \\
Gl tract & 2 & 1 & 10 \\
GU tract & 2 & 1 & 2 \\
Mucosa & 5 & 2 & 10 \\
Skin & 7 & 9 & 15 \\
Fever & 8 & 10 & 22 \\
Other & 2 & 1 & 9 \\
Maximum WHO 2 & 18 & 17 & 30 \\
Maximum WHO 3 & 12 & 12 & 39 \\
Maximum WHO 4 & 1 & 1 & 5
\end{tabular}

Gl tract indicates gastrointestinal tract; and GU tract, genito-urethral tract.

these reports, this cytogenetic abnormality has been detected by FISH, which is more sensitive than conventional chromosome techniques. In the present study, initiated in 1995, and based solely on cytogenetic analysis, we found that in addition to chromosome 13 deletions, chromosome 1p/q abnormalities were of prognostic relevance with regard to EFS, TTP, and OS. This prognostic significance of abnormalities of chromosome 1p/q for outcome in high-dose treatment has not, to our knowledge, been previously reported. In addition, we found a strong correlation between the presence of these 2 abnormalities, which indicates that the role of chromosome $13 / 13 q$ deletions for the outcome of treatment in several studies may have to be re-evaluated in this respect. However, our results indicate that the outcome of patients with unfavorable prognostic factors including chromosome 13 abnormalities and 1p/q abnormalities will not be improved by intensification alone.

In conclusion, intensified chemotherapy followed by myeloablative therapy results in a higher complete response rate and a longer time to progression, but it does not lead to a better event-free and overall survival when applied as first treatment in previously untreated MM. In time, a longer follow-up of all patients included in the study is awaited. Definition of prognostic factors such as $\beta_{2}$-microglobulin and chromosomal aberrations may allow allocating patients in various prognostic subgroups to different therapeutic modalities in order to improve outcome.

\section{Acknowledgments}

A complete list of the members of the Dutch-Belgian HematoOncology Cooperative Study Group (HOVON) appears in the "Appendix." Rosalyn Slater contributed on behalf of the Dutch Working Party on Cancer Genetics and Cytogenetics (NWKGC). This study was performed as an investigation by the National Health Council of The Netherlands.

\section{Appendix}

Participating hospitals in this study: Gasthuisberg Hospital, Leuven, G. E. G. Verhoef, M. Delforge; Eemland Hospital, Amersfoort, M. H. H. Kramer, S. Wittebol; Academic Medical Center, Amsterdam, M. H. J. van Oers; Antoni van Leeuwenhoek Hospital, Amsterdam, J. W. Baars; Onze Lieve Vrouwe Gasthuis, Amsterdam, K. J. Roozendaal; Slotervaart Hospital, Amsterdam, J. W. Mulder; Gooi-Noord Hospital, Blaricum, H. P. 
Muller; Hospital de Baronie, Breda, O. J. L. Loosveld; Atrium Medical Center, Brunssum, P. Voogt; Bosch Medical Center, Den Bosch, H. A. M. Sinnige; Leyenburg Hospital, Den Haag, P. W. Wijermans; Albert Schweitzer Hospital, Dordrecht, J. P. H. B. Sybesma, H. W. A. Berenschot; Medical Spectrum Twente, Enschede, M.R. Schaafsma; St Anna Hospital, Geldrop, A. E. M. Smals; Groene Hart Hospital, Gouda, K. J. Heering; Academic Hospital Groningen, E. Vellenga; Hospital Kennemer Gasthuis, Haarlem, P. W. G. van der Linden; Spaarne Hospital, Haarlem, A. B. Arntzenius; Atrium Medical Center, Heerlen, P. Voogt; Medical Center Leeuwarden, Leeuwarden, P. Joosten; Leiden University Medical Center, W. E. Fibbe; Rijnland Hospital, Leiderdorp, M. Boekhout; Academic Hospital Maastricht, Maastricht, H. C. Schouten; St Antonius Hospital, Nieuwegein, D. H. Biesma; University Medical Center St Radboud, Nijmegen, A. J. Croock- ewit, R. A. P. Raymakers; Waterlandhospital, Purmerend, H. J. Blomberg; Franciscus Hospital, Roosendaal, D. J. de Gooyer, J. T. P. Janssen; Erasmus Medical Center, Rotterdam, J. J. Cornelissen, C. M. Segeren, P. Sonneveld; Sint Franciscus Gasthuis, Rotterdam, H. C. T. van Zaanen, J. G. Pegels; Haven Hospital, Rotterdam, A. G. C. Bauer; Ikazia Hospital, Rotterdam, M. G. A. Baggen; Medical Center Rijnmond-Zuid, Rotterdam, A. A. van Houten; Vlietland Hospital, Schiedam, J. J. Braun; Maasland Hospital, Sittard, H. N. L. M. Bron; Ruwaard van Putten Hospital, Spijkenisse, M. H. Silbermann; Hospital Zeeuws Vlaanderen, Terneuzen, T. Hoyset; Diaconessenhuis, Utrecht, H. D. Eggink; University Medical Center Utrecht, Utrecht, H. M. Lokhorst; Hospital St Jansgasthuis, Weert, P. J. de Haan; Hofpoort Hospital, Woerden, J. Holleman; and Isala Klinieken, Zwolle, M. van Marwijk Kooy.

\section{References}

1. Alexanian R, Haut A, Khan AU, et al. Treatment for multiple myeloma. Combination chemotherapy with different melphalan dose regimens. JAMA. 1969;208:1680-1685

2. Alexanian R, Dimopoulos M. The treatment of multiple myeloma. N Engl J Med. 1994;330:484489.

3. Gregory WM, Richards MA, Malpas JS. Combination chemotherapy versus melphalan and prednisolone in the treatment of multiple myeloma: an overview of published trials. J Clin Oncol. 1992;10:334-342.

4. Group MTC. Combination chemotherapy versus melphalan plus prednisone as treatment for multiple myeloma: an overview of 6633 patients from 27 randomized trials. Myeloma Trialists' Collaborative Group. J Clin Oncol. 1998;16:3832-3842.

5. McElwain TJ, Powles RL. High-dose intravenous melphalan for plasma-cell leukaemia and myeloma. Lancet. 1983;2:822-824.

6. Selby PJ, McElwain TJ, Nandi AC, et al. Multiple myeloma treated with high dose intravenous melphalan. Br J Haematol. 1987;66:55-62.

7. Attal M, Huguet F, Schlaifer D, et al. Intensive combined therapy for previously untreated aggressive myeloma. Blood. 1992;79:1130-1136.

8. Harousseau JL, Milpied N, Laporte JP, et al. Double-intensive therapy in high-risk multiple my eloma. Blood. 1992;79:2827-2833.

9. Barlogie B, Jagannath S, Vesole D, Tricot G. Autologous and allogeneic transplants for multiple myeloma. Semin Hematol. 1995;32:31-44.

10. Bjorkstrand B, Ljungman P, Bird JM, et al. Autologous stem cell transplantation in multiple myeloma: results of the European Group for Bone Marrow Transplantation. Stem Cells. 1995; 13(suppl 2):140-146.

11. Harousseau JL, Attal M, Divine M, et al. Autologous stem cell transplantation after first remission induction treatment in multiple myeloma: a report of the French Registry on autologous transplantation in multiple myeloma. Blood. 1995;85:30773085.

12. Fermand JP, Ravaud P, Chevret S, et al. Highdose therapy and autologous blood stem cell transplantation in multiple myeloma: preliminary results of a randomized trial involving $167 \mathrm{pa}-$ tients. Stem Cells. 1995;13(suppl 2):156-159.

13. Bensinger WI, Rowley SD, Demirer T, et al. High dose therapy followed by autologous hematopoietic stem-cell infusion for patients with multiple myeloma. J Clin Oncol. 1996;14:1447-1456.

14. Fermand JP, Ravaud P, Chevret S, et al. Highdose therapy and autologous peripheral blood stem cell transplantation in multiple myeloma: up-front or rescue treatment? Results of a multicenter sequential randomized clinical trial. Blood. 1998;92:3131-3136.

15. Alegre A, Diaz-Mediavilla J, San-Miguel J, et al.
Autologous peripheral blood stem cell transplantation for multiple myeloma: a report of 259 cases from the Spanish Registry. Spanish Registry for Transplant in MM (Grupo Espanol de Trasplante Hematopoyetico-GETH) and PETHEMA. Bone Marrow Transplant. 1998;21:133-140.

16. Lokhorst HM, Sonneveld P, Cornelissen JJ, et al Induction therapy with vincristine, adriamycin, dexamethasone (VAD) and intermediate-dose melphalan (IDM) followed by autologous or allogeneic stem cell transplantation in newly diagnosed multiple myeloma. Bone Marrow Transplant. 1999;23:317-322.

17. Lenhoff $\mathrm{S}$, Hjorth $M$, Holmberg $E$, et al. Impact on survival of high-dose therapy with autologous stem cell support in patients younger than 60 years with newly diagnosed multiple myeloma: a population-based study. Nordic Myeloma Study Group. Blood. 2000;95:7-11.

18. Bjorkstrand $B$, Hagman A, Ljungman $P$, et al. Au tologous stem cell transplantation in multiple myeloma-an update of the EBMT registry. VIII International Myeloma Workshop. Banff, Canada; 2001:141.

19. Attal M, Harousseau JL, Stoppa AM, et al. A prospective, randomized trial of autologous bone marrow transplantation and chemotherapy in multiple myeloma. Intergroupe Francais du Myelome. N Engl J Med. 1996;335:91-97.

20. Atkins CD. High-dose chemotherapy in multiple myeloma. N Engl J Med. 1996;335:1844-1845.

21. Attal M, Harousseau JL, Michaux JL, et al. Single versus double transplant in myeloma: a randomized trial of the Inter Groupe Francophone du Myelome (IFM). Blood. 2000;96:557a

22. Cavo M, Tosi P, Zamagni E, et al. The "Bologna 96" clinical trial of single vs double PBSC transplantation for previously untreated MM:results of an interim analysis. VIII International Myeloma Workshop. Banff, Canada; 2001:29-30.

23. Fermand JP, Levy V, Ravaud P, et al. Single versus tandem high dose therapy (HDT) supported with autologous blood stem cell (ABSC) transplantation using unselected or CD-34 enriched ABSC: preliminary results of a two by two designed randomized trial in 230 young patients with multiple myeloma. VIII International Myeloma Workshop. Banff, Canada; 2001:147.

24. Durie BG, Salmon SE. A clinical staging system for multiple myeloma. Correlation of measured myeloma cell mass with presenting clinical features, response to treatment, and survival. Cancer. 1975;36:842-854.

25. Segeren $\mathrm{CM}$, Sonneveld $\mathrm{P}$, van der Holt $\mathrm{B}$, et al Vincristine, doxorubicin and dexamethasone (VAD) administered as rapid intravenous infusion for first-line treatment in untreated multiple myeloma. Br J Haematol. 1999;105:127-130.

26. Lokhorst HM, Sonneveld P, Wijermans PW, et al.
Intermediate-dose melphalan (IDM) combined with G-CSF (filgrastim) is an effective and safe induction therapy for autologous stem cell transplantation in multiple myeloma. Br J Haematol. 1996;92:44-48.

27. ISCN. An international system for human cytoge netic nomenclature. In: Mitelman F, ed; Basel, Switzerland: Karger; 1995.

28. Aaronson NK, Ahmedzai S, Bergman B, et al. The European Organization for Research and Treatment of Cancer QLQ-C30: a quality-of-life instrument for use in international clinical trials in oncology. J Natl Cancer Inst. 1993;85:365-376.

29. Freedman LS. Tables of the number of patients required in clinical trials using the logrank test. Statistics in Medicine. 1882;1:121-129.

30. Barlogie B, Jagannath S, Vesole DH, et al. Superiority of tandem autologous transplantation over standard therapy for previously untreated multiple myeloma. Blood. 1997;89:789-793.

31. Barlogie B, Jagannath S, Desikan KR, et al. Total therapy with tandem transplants for newly diagnosed multiple myeloma. Blood. 1999;93:55-65.

32. Attal M, Harousseau JL, Facon T, et al. Single versus double transplant in myeloma: a randomized trial of the "Inter Groupe Francais du Myelome" (IFM). Blood. 1999;94:714a

33. Goldschmidt $\mathrm{H}$, Hegenbart $\mathrm{U}$, Wallmeier $\mathrm{M}$, et al High-dose therapy with peripheral blood progenitor cell transplantation in multiple myeloma. Ann Oncol. 1997:8:243-246.

34. Moreau P, Facon T, Attal M, et al. Comparison of $200 \mathrm{mg} / \mathrm{m}$ (2) melphalan and 8 Gy total body irradiation plus $140 \mathrm{mg} / \mathrm{m}(2)$ melphalan as conditioning regimens for peripheral blood stem cell transplantation in patients with newly diagnosed multiple myeloma: final analysis of the Intergroupe Francophone du Myelome 9502 randomized trial. Blood. 2002;99:731-735.

35. Bjorkstrand BT, Svensson H, Goldschmidt H, et al. 5489 autotransplants in multiple myeloma-a registry study from the European Group for Blood and Bone Marrow Transplantation (EBMT). Blood. 1999;94:715a.

36. Zojer N, Konigsberg R, Ackermann J, et al. Deletion of $13 q 14$ remains an independent adverse prognostic variable in multiple myeloma despite its frequent detection by interphase fluorescence in situ hybridization. Blood. 2000;95:1925-1930.

37. Konigsberg R, Zojer N, Ackermann J, et al. Predictive role of interphase cytogenetics for survival of patients with multiple myeloma. J Clin Oncol. 2000;18:804-812.

38. Facon T, Avet-Loiseau H, Guillerm G, et al. Chromosome 13 abnormalities identified by FISH analysis and serum beta2- microglobulin produce a powerful myeloma staging system for patients receiving high-dose therapy. Blood. 2001;97: 1566-1571. 